\title{
ON THE COVER
}

\section{South Branch Sunset by Tim Karas}

Portions of the following are based on an interview with the artist on May 8, 2019.

"I'm always looking for new ways of seeing the worldit's all about seeing the world-capturing moments that won't happen again in the same way," said photographer Tim Karas. He came to that realization on his own but was encouraged by artist and photography professor at Northeastern Illinois University Don Bulucos, who had a strong influence on Karas's art. Bulucos would admonish him to not only look at what he was photographing but look around to see what other-perhaps more interesting-images were there.

Karas, majoring in business administration, needed a humanities course, and because he had had years of previous photography experience he chose a photography course to satisfy the requirement. He responded to Bulucos's effervescent personality and his edgy artistry. Bulucos favored unusual lighting and angles, producing interesting ways of seeing the world. He was also a consummate professional. Karas remembered one wintry Chicago day when he went downtown to search for leading lines-those lines that draw the viewer into an image. He found what he was looking for in snow on stairways. He took the film back to the darkroom and spent 6 to $7 \mathrm{hr}$ trying to get the snow to look right. Bulucos repeatedly told him the snow did not look like snow. It was a matter of getting the light, shadows, and highlights right. In those days, a photographer had to do this in the darkroom. Karas says that nowadays his computer has become the equivalent of a darkroom. He shoots in RAW, an uncompressed image that needs basic processing after the image is captured.

Karas was fortunate to find Bulucos but stated that his passion for photography started with his father. His father always had a camera with him and took pictures all over Chicago. When Tim turned 5, his father gave him his first camera-a Brownie Fiesta (which he still has). His father was the unofficial photographer of his Navy ship during World War II. He sent his film back to his brother, Casimir (Tim's uncle), to be developed and created a treasure trove of images of ship life during the war. Tim's Uncle Casimir was a Hollywood photographer to the stars, especially Jean Harlow, who loved his work, according to family lore. Casimir volunteered to spy for the Polish government in London and was killed in action during the war. The Karas family had come to the United States from Poland at the time of World War I.

In high school, Tim joined the photography club but still considered photography a hobby. He took action pictures of sporting events for the school newspaper, and his pictures appeared in the yearbook as well. "If you have a fast moving subject, you have to be quick too," he said. This experience taught him to "get it right in the camera." He is happiest with landscapes, both natural and human-made (Chicago is known for its diverse architecture).

Infrared photography intrigues Karas because of its otherworldly look-a different way to see the world. He learned that an ancestor served the Union in the Civil War, which led Tim to stand on Little Round Top, where his great, great grandfather fought to save that Gettysburg hill. Karas said he realized what it might have felt like to know you cannot move in order to hold the high ground. Later, looking at the ghostly infrared images showed him an unusual perspective and brought an even greater appreciation of the emotional drama of war. It's a subject he continues to explore in one of his ongoing projects.

The image on the cover, South Branch Sunset, is an example of a different perspective on a sunset. It was taken looking north, not west. The light of the setting sun highlights the windows of the skyscrapers and lower buildings in the distance. The tallest building with the golden stripe of sunlight was originally known as the Sears Tower (and still it's called that by most lifelong Chicagoans), now officially called the Willis Tower. The picture was taken on a summer evening from one of his favorite vantage points, the 18th Street Bridge. The leaning structure is a bascule bridge named for the mechanism that raises and lowers the bridge. The South Branch of the Chicago River creates the "leading line," taking the viewer into the image. Chicago owes its existence to the river, which has been cleaned up considerably, to the point where people-such as those in the small boat-use it for recreational boating. The larger, yellow boat is a water taxi. For Karas, this image summarizes what Chicago is all about: the bridge symbolizes industry, the buildings are the architectural essence of the city, and the river symbolizes the people and their life in this urban setting.

Sandra M. Fowler Art Co-Editor 